Justine A. Ellis · Sianna Panagiotopoulos

Aysel Akdeniz · George Jerums · Stephen B. Harrap

\title{
Androgenic correlates of genetic variation in the gene encoding $5 \alpha$-reductase type 1
}

Received: 11 March 2005/ Accepted: 27 July 2005/Published online: 10 September 2005

(C) The Japan Society of Human Genetics and Springer-Verlag 2005

\begin{abstract}
Androgens determine male secondary sexual characteristics and influence a variety of metabolic pathways. Circulating levels of androgens are highly heritable; however, the genes involved are largely unknown. The $5 \alpha$-reductase enzymes types 1 and 2 responsible for converting testosterone to the more potent androgen dihydrotestosterone are encoded by the SRD5A1 and SRD5A2 genes, respectively. We performed indirect genetic association studies of SRD5AI and $S R D 5 A 2$ and the dihydrotestosterone/testosterone ratio that reflects the activity of $5 \alpha$-reductase in 57 males with type 2 diabetes. We found evidence of significant association between a single nucleotide polymorphism in SRD5A1 and the dihydrotestosterone/testosterone ratio (median 0.10, interquartile range 0.08 vs. median 0.06 , interquartile range $0.04, P=0.009$ ). The polymorphism was not associated with any diabetic phenotypes. These results suggest that functional genetic variants might exist in or around $S R D 5 A 1$ that affect the activity of the $5 \alpha$-reductase enzyme type 1 and influence androgen levels.
\end{abstract}

Keywords Androgen - Testosterone · Dihydrotestosterone $\cdot$ Single nucleotide polymorphism $\cdot$ Genetic association $\cdot$ Insulin

\footnotetext{
J. A. Ellis $(\bowtie) \cdot$ S. B. Harrap

Department of Physiology, The University of Melbourne,

Melbourne, Victoria, 3010, Australia

E-mail: justine@unimelb.edu.au

Tel.: + 61-3-83440243

Fax: $+61-3-83445818$

S. Panagiotopoulos $\cdot$ A. Akdeniz $\cdot$ G. Jerums

Endocrinology Unit, Austin and Repatriation Medical Centre, Heidelberg, Victoria, 3084, Australia
}

\section{Introduction}

The biological roles of androgens are diverse. Not only do androgens determine male sexual characteristics but they are also believed to be directly or indirectly involved in other biological systems such as insulin (Livingstone and Collison 2002) and lipid metabolism (Wu and von Eckardstein 2003), bone growth and resorption (Vanderschueren et al. 2004), and hair follicle cycling (Randall 1997). There are two predominant androgens: testosterone (T) and its metabolite dihydrotestosterone (DHT). Both of these androgens act through the same androgen receptor; however, DHT binds with higher affinity and is therefore the more potent androgen (Janne et al. 1993).

Androgen levels change dramatically during puberty, especially in males. However, in adulthood it has been demonstrated that a substantial proportion of the variation in circulating levels of androgens can be ascribed to genetic factors. Twin studies in men have demonstrated heritability estimates of $85 \%$ and $96 \%$ for production rates of T and DHT, respectively (Meikle et al. 1988). The enzyme $5 \alpha$-reductase is responsible for the reduction of T to DHT and is therefore a key controlling enzyme in determining T and DHT levels. The DHT/T ratio, an indicator of $5 \alpha$-reductase activity, shows significant heritability itself and has been demonstrated in male twin studies to be in the order of $42 \%$ (Meikle et al. 1986).

There are two isoforms of $5 \alpha$-reductase, encoded by separate genes. Type $15 \alpha$-reductase is encoded by SRD5A1 on chromosome 5 (Jenkins et al. 1991), and type $25 \alpha$-reductase is encoded by SRD5A2 on chromosome 2 (Thigpen et al. 1993). These isoforms differ in biochemical properties such as optimum $\mathrm{pH}$ and sensitivity to substrates (Jenkins et al. 1992). The tissue distribution of the genes encoding these isoforms also differs. While both SRD5A1 and SRD5A2 are expressed in many tissues, type $25 \alpha$-reductase predominates in the prostate and type $15 \alpha$-reductase is 
more highly expressed in tissues such as liver, muscle, skin, and brain (Genecards: http://bioinformatics.weizmann.ac.il/cards). The differences in properties and tissue expression suggest that the two isoforms may play distinct tissue-specific and, therefore, biological roles.

Among the metabolic actions of the androgens, they appear to play a role in determining insulin sensitivity in men (Livingstone and Collison 2002). Additionally, $5 \alpha-$ reductase expression has been demonstrated in insulinsensitive tissues such as liver and muscle. Therefore, androgens might be relevant to insulin and possibly to type 2 diabetes.

Based on the hypothesis that genetic variation in or around the $S R D 5 A 1$ or $S R D 5 A 2$ genes might alter the expression or function of their encoded $5 \alpha$-reductase enzymes, we reasoned that this might be evident through the phenotype of the DHT/T ratio. Such variation might also be of special relevance to individuals with type 2 diabetes in whom genetically-induced variation in insulin sensitivity might have clinical relevance. As part of an ongoing study of type 2 diabetes, we studied a group of 62 diabetic males to test for association between the $5 \alpha-$ reductase genes and $\mathrm{T}$ (total, free, and bioavailable), $\mathrm{DHT}$, and $\mathrm{DHT} / \mathrm{T}$ ratio.

\section{Materials and methods}

Subject recruitment and phenotype measurement

Sixty-two males diagnosed with type 2 diabetes were drawn from a larger study of diabetes and its complications as published previously (MacIsaac et al. 2004). All subjects gave informed consent, and the studies were sanctioned by the Human Experimentation Ethics Committee of Austin Health.

Blood samples were obtained from the 62 participants under fasting conditions for measurements of androgen levels. Serum was tested by radioimmunoassay for concentrations of T (Spectria, Orion Diagnostica), DHT (Diagnostica Systems Laboratories), sex hormone binding globulin (SHBG; Spectria, Orion Diagnostica), and insulin (Phadeseph). DHT/T and T/SHBG ratios were calculated from appropriate measurements. Free and bioavailable $\mathrm{T}$ were calculated using SHBG and albumin (see below) measures, according to the method of Vermeulen et al. (1999).

Blood was also taken for genetic analyses (see below) and for estimates of insulin, hemoglobin A1c (HbAlc), and albumin. Urine was collected for measurement of urinary albumin excretion rates (AER). Serum albumin was measured by automated Bromo Cresol Purple (BCP) method (Hitachi 911/747), and urinary AER was measured by immunoturbidimetry (Dade-Behring; MacIsaac et al. 2004). HbA1c was measured by automated HPLC (Biorad Diamat).

Phenotypic data including age and body mass index (BMI) were usually collected at the same time as blood sampling, but in all cases within 1 year of blood collection.

Analysis of the SRD5A1 and SRD5A2 single nucleotide polymorphisms (SNPs)

DNA was extracted from blood samples using standard phenol-chloroform techniques. Each DNA sample was genotyped for the HinfI and NspI restriction fragment length polymorphism (RFLP) single nucleotide polymorphism (SNP) of the SRD5Al gene and for the RsaI RFLP SNP of the SRD5A2 gene, as previously described (Ellis et al. 1998).

\section{Statistical analyses}

Data were summarized as mean [standard deviation (SD)] and median [interquartile range (IQR)]. Correlations between phenotypes were tested using a nonparametric Spearman two-tailed correlation method. The associations between genotypes and phenotypes were assessed using analysis of variance (ANOVA) that adjusted for the effects of age and BMI. In recognition of the nonnormality of the phenotype distribution for some genotype groups, associations were further tested using the Kruskal-Wallis rank test, a nonparametric analogue of one-way ANOVA. A $P$ value $<0.05$ was considered significant. Analyses were performed using the SPSS (Macintosh version 11) statistical software package.

\section{Results}

Of the 62 participants in this study, three were excluded from analysis on the basis of a total testosterone measurement of $<5 \mathrm{nmol} / 1$ that suggested a clinical derangement of androgens. Of the remaining 59 participants, serum albumin and AER measures were unavailable in two subjects (preventing the calculation of free and bioavailable T), and BMI data were unavailable in five subjects. Data from these subjects were included in the analyses when possible.

Table 1 shows the phenotypic data of the 59 type 2 diabetic males in this analysis. Subjects on average showed fasting hyperinsulinemia and elevated HbAlc levels. A total of $76 \%$ of the patients had urinary AERs $>20 \mu \mathrm{g} / \mathrm{min}$ (microalbuminuria threshold). Serum albumin was normal on average, and no patient had hypoalbuminemia or proteinuria in the nephrotic range $(<30 \mathrm{~g} / \mathrm{l}$ and $>2,000 \mu \mathrm{g} / \mathrm{min}$, respectively). The average levels of T and DHT were within the reference ranges for the assays.

Correlation analyses showed that with increasing age, there were lower levels of free $(r=-0.32, P=0.02)$ and bioavailable $\mathrm{T}(r=-0.40, P<0.01)$ and of the $\mathrm{T} /$ SHBG ratio $(r=-0.45, P<0.01)$. No significant cor- 
Table 1 Phenotypes of type 2 diabetic males participating in the study ( $S D$ standard deviation, $I Q R$ interquartile range, $B M I$ body mass index, $T$ testosterone, $D H T$ dihydrotestosterone, $S H B G$ sex hormone binding globulin, $A E R$ albumin excretion rate, $H b A l c$ hemoglobin A1c)

Phenotype

\begin{tabular}{lll}
\hline Age & Mean (SD) & $64.4 \mathrm{years}(10.5)$ \\
& Median (IQR) & $67.0 \mathrm{years}(12.0)$ \\
BMI & Mean (SD) & $28.6 \mathrm{~kg} / \mathrm{m}^{2}(4.7)$ \\
& Median (IQR) & $27.9 \mathrm{~kg} / \mathrm{m}^{2}(4.5)$ \\
Total T & Mean (SD) & $448.6 \mathrm{ng} / \mathrm{dl}(162.9)$ \\
& Median (IQR) & $417.6 \mathrm{ng} / \mathrm{dl}(213.1)$ \\
Free T & Mean (SD) & $8.5 \mathrm{ng} / \mathrm{dl}(2.9)$ \\
& Median (IQR) & $8.5 \mathrm{ng} / \mathrm{dl}(3.4)$ \\
Bioavailable T & Mean (SD) & $191.0 \mathrm{ng} / \mathrm{dl}(67.0)$ \\
& Median (IQR) & $188.0 \mathrm{ng} / \mathrm{dl}(77.5)$ \\
DHT & Mean (SD) & $1.1 \mathrm{nmol} / 1(0.6)$ \\
& Median (IQR) & $0.9 \mathrm{nmol} / 1(0.7)$ \\
DHT/total T ratio & Mean (SD) & $0.07(0.05)$ \\
& Median (IQR) & $0.06(0.04)$ \\
SHBG & Mean (SD) & $41.7 \mathrm{nmol} / 1(19.2)$ \\
& Median (IQR) & $39.1 \mathrm{nmol} / 1(28.5)$ \\
Total T/SHBG ratio & Mean (SD) & $42.5(18.6)$ \\
& Median (IQR) & $38.7(17.7)$ \\
Insulin & Mean (SD) & $16.7 \mu \mathrm{U} / \mathrm{ml}(9.4)$ \\
& Median (IQR) & $14.6 \mu \mathrm{U} / \mathrm{ml} \mathrm{(11.9)}$ \\
Serum albumin & Mean (SD) & $40.1 \mathrm{~g} / 1(4.0)$ \\
& Median (IQR) & $41.0 \mathrm{~g} / 1(6.0)$ \\
AER & Mean (SD) & $317.0 \mu \mathrm{g} / \mathrm{min}(723.7)$ \\
& Median (IQR) & $34.0 \mu \mathrm{mg} / \mathrm{min}(128.8)$ \\
HbAlc & Mean (SD) & $8.0 \%(1.6)$ \\
& Median (IQR) & $8.0 \%(2.2)$ \\
\hline
\end{tabular}

Note: Both means and medians are presented for consistency with Table 2, since the phenotype distribution was not always normal when broken down by genotype relations between these hormonal variables and BMI were observed. In addition, neither DHT nor the $\mathrm{DHT} / \mathrm{T}$ ratio correlated with age or BMI. No significant associations were observed between insulin levels and any of the physiological or hormonal phenotypes.

Genotyping was successful in 57 participants for the SRD5A1HinfI SNP (Table 2). The allele defined by the absence $(A)$ of the SRD5A1HinfI restriction site was less common $(45 \%)$ than the allele defined by its presence $(B, 55 \%)$. The observed genotypes $(A A=9$, $A B=33, B B=15)$ were in Hardy-Weinberg equilibrium. When grouped according to these genotypes, ANOVA with adjustments for age and BMI revealed that individuals homozygous for the "A" allele had significantly higher $\mathrm{DHT} / \mathrm{T}$ ratios than those in the other genotype groups (0.12, SD: 0.09 vs. 0.06, SD: 0.02 ; $P<0.001)$. Due to small numbers of "AA" individuals, normality of the phenotype distribution was difficult to confirm, and hence the nonparametric Kruskal-Wallis ranking test was also employed to confirm the result $(P=0.009)$. No other statistically significant $S R D 5 A 1$ genotype-related differences were observed for other androgen phenotypes using either ANOVA or Kruskal-Wallis tests (data not shown). No associations were observed between $S R D 5 A 1$ genotypes and duration of diabetes, insulin levels, HbAlc, or AER.

No phenotype differences were observed between groups defined by the SRD5A1 NspI or the SRD5A2 RsaI SNPs.

Table 2 Measured phenotypes in genotype groups of the $S R D 5 A 1 H i n f I$ SNP ( $T$ testosterone, $S D$ standard deviation, $I Q R$ interquartile range, $D H T$ dihydrotestosterone, $S H B G$ sex hormone binding globulin)

\begin{tabular}{|c|c|c|c|c|}
\hline \multirow[t]{2}{*}{ Phenotype } & & \multicolumn{3}{|c|}{ SRD5A1 HinfI genotype } \\
\hline & & $\mathrm{AA}(n=9)$ & $\mathrm{AB}(n=33)^{\mathrm{a}}$ & $\mathrm{BB}(n=15)^{\mathrm{b}}$ \\
\hline \multirow[t]{2}{*}{$\mathrm{T}(\mathrm{ng} / \mathrm{dl})$} & Mean (SD) & 386.9 (219.8) & $452.6(173.2)$ & $455.4(86.4)$ \\
\hline & Median (IQR) & $247.7(357.2)$ & $394.6(214.5)$ & $449.3(164.1)$ \\
\hline \multirow{2}{*}{ Free T (ng/dl) } & Mean (SD) & $6.6(2.3)$ & $8.3(2.6)$ & $9.3(2.8)$ \\
\hline & Median (IQR) & $5.8(3.2)$ & $8.5(2.9)$ & $8.9(3.3)$ \\
\hline \multirow[t]{2}{*}{ Bioavailable T (ng/dl) } & Mean (SD) & $148.9(46.7)$ & $189.7(61.1)$ & $199.2(63.9)$ \\
\hline & Median (IQR) & $142.0(76.0)$ & $185.0(71.5)$ & $200.0(62.5)$ \\
\hline \multirow[t]{2}{*}{ DHT (nmol/l) } & Mean (SD) & $1.4(0.9)$ & $1.0(0.5)$ & $1.0(0.4)$ \\
\hline & Median (IQR) & $1.0(1.4)$ & $0.9(0.7)$ & $0.8(0.8)$ \\
\hline \multirow[t]{2}{*}{$\mathrm{DHT} / \mathrm{T}^{\mathrm{ratio}}{ }^{\mathrm{c}}$} & Mean (SD) & $0.12(0.09)$ & $0.07(0.03)$ & $0.06(0.02)$ \\
\hline & Median (IQR) & $0.10(0.08)$ & $0.06(0.04)$ & $0.06(0.05)$ \\
\hline \multirow[t]{2}{*}{ SHBG } & Mean (SD) & $41.7(26.3)$ & $43.6(19.4)$ & $39.4(15.1)$ \\
\hline & Median (IQR) & $27.5(34.8)$ & $40.0(29.5)$ & $43.0(27.6)$ \\
\hline \multirow[t]{2}{*}{$\mathrm{T} / \mathrm{SHBG}$} & Mean (SD) & $33.1(6.7)$ & $40.3(13.6)$ & $48.6(26.4)$ \\
\hline & Median (IQR) & $31.0(10.5)$ & $41.1(16.5)$ & $37.5(19.0)$ \\
\hline \multirow[t]{2}{*}{ Insulin $(\mu \mathrm{U} / \mathrm{ml})$} & Mean (SD) & $18.3(7.4)$ & $17.2(10.7)$ & $13.7(5.2)$ \\
\hline & Median (IQR) & $19.1(10.9)$ & $14.3(14.4)$ & $14.4(8.1)$ \\
\hline
\end{tabular}

${ }^{\mathrm{a}} n=32$ for free $\mathrm{T}$ phenotypes

${ }^{\mathrm{b}} n=14$ for bioavailable T phenotypes

${ }^{\mathrm{c}} P<0.001 \mathrm{AA}$ vs. other genotype groups by age- and BMI-adjusted ANOVA, and $P=0.009$ by Kruskal-Wallis nonparametric rank test Allele " $\mathrm{A} "=$ absence, allele " $\mathrm{B} "=$ presence of restriction site

Note: Both means and medians are presented because phenotype distributions were not always normal for each of the three genotype groups, even when the overall distribution of the phenotype was normal 


\section{Discussion}

This study represents a preliminary investigation of the hypothesis that genes controlling androgen levels might contribute to variation in serum androgen concentrations. The study was predicated on the known heritability of androgen levels and the DHT/T ratio, which is indicative of the activity of the $5 \alpha$-reductase enzymes. We found a significant association between a SNP in the gene encoding type I $5 \alpha$-reductase (SRD5A1), and the serum DHT/T ratio. Individuals homozygous for the "A" allele had a significantly higher ratio, almost double that found in the other genotype groups. This is indicative of increased conversion of T to DHT in the "A" homozygotes, consistent with increased $5 \alpha$-reductase enzyme activity. Although the SNP marker used in this study has no known consequence for the amino acid sequence of the enzyme, the results suggest that one or more functional variants exist in or around this gene that are in linkage disequilibrium with our marker.

The associations detected between the SRD5A1HinfI RFLP and androgen levels were not observed for the SRD5A1NspI RFLP. The two SNPs are not in tight linkage disequilibrium ( $\mathrm{LD}, r^{2}=0.45$, data not shown) despite their relatively close proximity to each other. This phenomenon does not appear to be unusual, and the patterns of linkage disequilibrium throughout the genome, and indeed within individual genes, are proving to be very complex (Martin et al. 2000). This lack of tight LD, especially in the sample size used in this study, is likely to account for the lack of association with the NspI RFLP.

No associations were detected between SRD5A2 and the DHT/T ratio or any other of the androgen phenotypes. The relative influence of the two $5 \alpha$-reductase isoenzymes on the plasma levels of androgens has not been clearly differentiated. Our observations might suggest that genetically programmed changes in function of the type 1 isoenzyme can be important for plasma androgen.

From this study, we cannot automatically extrapolate the association between $S R D 5 A 1$ and DHT/T ratio to the general population. However, there appear to be no special relationships between the genotypes and diabetes. We found no evidence of an association between insulin and androgen levels in these diabetics, nor did we detect any association between the polymorphisms studied and any other measured diabetic phenotypes such as HbAlc or AER. Additionally, the androgen levels were within the normal population distribution, and allele frequencies of the SRD5A1 SNP were not different from those found in a previous study of the general population (minor allele frequency $44.7 \%$ vs. $48.6 \%, P=0.50$; Ellis et al. 1998). These data suggest that the SRD5Al gene contains functional polymorphism important to enzyme activity but of no special relevance to diabetes or its complications.

In summary, we have found evidence of a functional polymorphism of the SRD5Al gene associated with an approximate doubling of the DHT/T ratio. Our findings are likely to represent one component explaining the heritability of sex steroid variation. It remains to be seen whether the SRD5A1 SNP is relevant to androgen phenotypes in larger studies in the general population. Identifying such associations would significantly benefit our understanding of the many conditions in which sex steroids are relevant.

Acknowledgements We thank Professor Jean Kaufman, Department of Endocrinology, University Hospital, Ghent, Belgium, for supplying the free testosterone calculator, and Dr. Katrina Scurrah, Department of Physiology, University of Melbourne, for statistical advice.

\section{References}

Ellis JA, Stebbing M, Harrap SB (1998) Genetic analysis of male pattern baldness and the $5 \alpha$-reductase genes. J Invest Dermatol 110:849-853

Janne OA, Palvimo JJ, Kallio P, Mehto M (1993) Androgen receptor and mechanism of androgen action. Ann Med 25:8389

Jenkins EP, Hseih $\mathrm{CH}$, Milatovich A, Normington $\mathrm{K}$, Berman DM, Francke U, Russell DW (1991) Characterisation and chromosomal mapping of a human steroid $5 \alpha$-reductase gene and pseudogene and mapping of the mouse homologue. Genomics 11:1102-1112

Jenkins EP, Andersson S, Imperato-McGinley J, Wilson JD, Russell DW (1992) Genetic and pharmacological evidence for more than one human steroid $5 \alpha$-reductase. J Clin Invest 89:293-300

Livingstone C, Collison M (2002) Sex steroids and insulin resistance. Clin Sci 102:151-166

MacIsaac R, Tsalamandris C, Panagiotopoulos S, Smith TJ, McNeil KJ, Jerums G (2004) Nonalbuminuric renal insufficiency in type 2 diabetes. Diabetes Care 27:195-200

Martin ER, Lai EH, Gilbert JR, Rogala AR, Afshari AJ, Riley J, Finch KL, Stevens JF, Livak KJ, Slotterbeck BD, Slifer SH, Warren LL, Conneally PM, Schmechel DE, Purvis I, PericakVance MA, Roses AD, Vance JM (2000) SNPing away at complex diseases: analysis of single-nucleotide polymorphisms around APOE in Alzheimer disease. Am J Hum Genet 67:383394

Meikle AW, Bishop DT, Stringham JD, West DW (1986) Quantitating genetic and non-genetic factors that determine plasma sex steroid variation in normal male twins. Metabolism 35:1090-1095

Meikle AW, Stringham JD, Bishop T, West DW (1988) Quantitating genetic and non-genetic factors influencing androgen production and clearance rates in men. $\mathbf{J}$ Clin Endocrinol Metab 67:104-109

Randall VA (1997) The role of androgens in the regulation of the human hair follicle. In: Azziz R, Nestler JE, Dewailly D (eds) Androgen excess disorders in women. Lippincott-Raven, Philadelphia, pp 115-129

Thigpen AE, Silver RI, Guileyardo JM, Casey ML, McConnell JD, Russell DW (1993) Tissue distribution and ontogeny of steroid $5 \alpha$-reductase isozyme expression. J Clin Invest 92:903-910

Vanderschueren D, Vandenput L, Boonen S, Lindberg MK, Bouillon R, Ohlsson C (2004) Androgens and bone. Endocr Rev 25:389-425

Vermeulen A, Verdonck L, Kaufman JM (1999) A critical evaluation of simple methods for the estimation of free testosterone in serum. J Clin Endocrinol Metab 84:3666-3672

Wu FCW, von Eckardstein A (2003) Androgens and coronary artery disease. Endocr Rev 24:183-217 